УДК 378.016:796: [37.015.3:005.32]: 796.83

DOI https://doi.org/10.26661/2663-5925-2021-2-03

\title{
МОТИВАЦІЯ СТУДЕНТІВ АГРОТЕХНОЛОГІЧНИХ СПЕЦІАЛЬНОСТЕЙ ДО ЗАНЯТТЯ ФІЗИЧНОЮ КУЛЬТУРОЮ ЗАСОБАМИ БОКСУ
}

\author{
Воронцов А. I. \\ аспірант кафедри теорії та методики фізичної культури і спорту \\ Запорізький національний університет \\ вул. Жуковського, 66, Запоріжжя, Украӥна \\ orcid.org/0000-0002-3269-273X \\ vai77@ukr.net
}

Коломоєць В. А.

кандидат технічних наук,

дочент кафедри геоекології $і$ землеустрою

Таврійський державний агротехнологічний університет

імені Дмитра Моторного

просп. Богдана Хмельницького, 18, Мелітополь, Запорізька область, Украӥна

orcid.org/0000-0003-1375-0962

3kd320053@gmail.com

\begin{abstract}
Ключові слова: заклади вищчої освіти, фізичне виховання, студентська молодь, тренувальні програми, перебудова прочесу навчання, мотивація.
\end{abstract}

У статті обгрунтовано доцільність навчання засобами боксу, що підвищить зацікавленість до занять фізичною культурою у студентів. Мета статті - теоретично обгрунтувати доцільність занять засобами боксу на уроках фізичної культури у студентів. Матеріали та методи: аналіз наукової літератури, метод узагальнення даних. Результати. Розглянуто емпіричні дані психофізіологічного стану студентів різних спеціальностей у закладах вищої освіти. Виявлено недостатній рівень фізичної підготовки у студентів, низька зацікавленість фізичною культурою як предметом у традиційному викладанні. Під час навчання не враховуються фази менструального циклу в жіночої статі. Вивчено навчальні програми з боксу для закладів вищої освіти, авторські тренувальні програми $з$ боксу для чоловічої та жіночої статі, у яких доведено можливість підвищення загальної фізичної підготовки, розвиток фізичних якостей засобами боксу. Запропоновано переглянути організаційно-методичні прийоми під час навчання засобами боксу на уроках з фізичної культури незалежно від статевої ознаки. Визначені засоби викладання техніки боксу на заняттях фізичною культурою. Доведено доцільність викладання за допомогою гендерно диферційного й ігрового методів під час навчання. Висновки: у статті обгрунтовано доцільність навчання засобами боксу на уроках фізичного виховання, що, по-перше, підвищить мотивацію до занять фізичною культурою, по-друге, дозволить опанувати навички виду спорту, по-третє, підвищить загальний рівень фізичної підготовки. Навчання гендерно диференційним та ігровим методами набуває актуальності, особливо щодо жіночої статі. Навчальну програму для студентів доцільно базувати на підготовчих вправах кваліфікованих боксерів. 


\title{
MOTIVATION OF STUDENTS OF ARGOTECHNOLOGICAL SPECIALTIES TO ENGAGE IN PHYSICAL CULTURE BY MEANS OF BOXING
}

\author{
Vorontsov A. I. \\ Postgraduate Student \\ Zaporizhzhia National University \\ Zhukovskoho str., 66, Zaporizhzhia, Ukraine \\ orcid.org/0000-0002-3269-273X \\ vai77@ukr.net \\ Kolomoec V. A. \\ Candidate of Technical Sciences, \\ Associate Professor at the Department of Hydraulic Hydraulics \\ Dmytro Motornyi Tavria State Agrotechnological University \\ Bogdana Khmelnytskgo ave., 18, Melitopol, Zaporizhzhia region, Ukraine \\ orcid.org/0000-0003-1375-0962 \\ 3kd320053@gmail.com
}

Key words: higher

education institutions, physical education, student youth, training programs, reorganization of learning process, motivation.
The article informed the expediency of teaching physical culture to students of higher educational institutions by means of boxing, which will increase the interest to exercise physical culture. The purpose of the articleto substantiate theoretically the expediency of boxing by means of physical culture among students. Materials and methods: analysis of scientific literature, method of data summarizing. The results. The empirical data of the psychophysiological state of students of different specialties in higher education institutions are considered. Insufficient level of physical training and fit of students, low interest in physical culture as an object in traditional teaching. In teaching, the phases of the menstrual cycle in a female gender are not taken into account. Learned Boxing Training Programs for Higher Education Institutions, Copyright Boxing Programs for Men's and Female. In which the possibility of increasing the general physical training, the development of physical qualities of boxing means is proved. It is proposed to review organizational and methodological techniques in teaching Boxes in physical education lessons regardless of the sexual character. Defined means of teaching boxing technique in physical education classes. The expediency of teaching with gender-divergent and gaming methods in training is proved. Conclusions: The article substantiates the expediency of booking by means of boxing in physical education, which will first increase the motivation to exercise physical culture, and secondly allow mastery of sports skills, and the third level of physical training will increase the overall level of physical training. Training gender-differential and gaming method becomes relevant especially to female gender. The curriculum for students is expedient to base on the preparatory exercises of qualified boxers.
Постановка проблеми. Натепер у зв'язку 3 визначенням концептуальних завдань, які відображені в нижчезазначених директивних документах: у Національній стратегії 3 оздоровчої рухової активності в Україні на період до 2025 p. «Рухова активність - здоровий спосіб життя - здорова нація», «Стратегії розвитку фізичної культури і спорту на період до 2028 р.», «Рекомендаціях щодо стратегічного розвитку фізичного виховання та спорту серед студентської молоді на період до 2025 р.», затверджених наказом Мініс- терства освіти і науки України від 15 лютого 2021 р. № 193, усе більше уваги приділяють фізичному розвитку студентів за допомогою відкриття спортивних клубів на базі закладів вищої освіти (далі - 3ВО), залучення студентів до спортивно-масових заходів. Але це не вирішує питань стосовно мотивації занять фізичною культурою в агротехнологічних ЗВО. Зазвичай тренери у студентських спортивних клубах працюють лише 3 активними особами або індивідуально, залежно від виду спорту. 
У викладанні фізичної культури, за визначенням науковців, спостерігається недосконалість системи реалізації різних напрямів рухової активності, які не відповідають вимогам соціальноекономічних умов життєдіяльності студентської молоді [1;2].

За дослідженнями науковців, доцільність занять за спортивною спрямованістю вирішує більший комплекс завдань, що стоять перед фізичним вихованням студентів, ніж традиційні заняття 3 фізичної культури [3, с. 193].

Мета статті - теоретично обгрунтувати доцільність занять засобами боксу на уроках фізичної культури.

Виклад основного матеріалу дослідження. Учений В. Вихор (2011р.) наводить дані, за якими у $65-68 \%$ випадках студенти мають незадовільний рівень психофізіологічного стану, тобто фізичної підготовки, функціональних можливостей, недостатній фізичний розвиток, незначні відхилення у стані здоров'я [4, с. 25].

Науковці В. Загородній, Л. Ярославська (2021 р.) зазначають, що за результатами оцінювання фізичної підготовленості студентів різних ЗВО, проведеного серед 1260 респондентів протягом 2018-2019 навчального року, виявлено 77,4\% студентів, які мали недостатній рівень фізичної підготовки [5, с. 57-58]. Пов'язують це з меншою кількістю рухової активності, особливо у вихідні дні, коли фізичні навантаження становлять лише $2 \%$, що замало для студентів, у яких ще відбувається природний фізичний розвиток. Мінімальна рухова активність має бути не менш 8-12 годин на тиждень для чоловіків та 6-10 годин на тиждень для жінок. Решта часу доповнюється побутовою діяльністю. Рекомендовано цілеспрямовані фізичні навантаження не менш 6-8 годин для чоловіків та 5-7 годин для жінок [5, с. 59].

У дослідженні студентів технологічного університету (235 осіб) зазначено, що в $1,9 \%$ низькій фізичний розвиток, у $56,6 \%$ - нижчий за середній, тільки $26,6 \%$ студентів показали вищий за середній рівень фізичного розвитку, $3,5 \%$ - високий розвиток серед [5, с. 60].

Фахівці І. Сопотова, О. Півень (2021 р.) також зазначають зниження рівня фізичної підготовленості у студентів взагалі. Наводять дані, за якими приблизно 60\% індивідів належать до спеціальної медичної групи [6, с. 91].

На особисту думку авторів статті, однією із причин таких показників $є$ мала зацікавленість студентів заняттями з фізичної культури, яка пов' язана із щільним щотижневим розкладом навчальних дисциплін, де зайняття фізичною культурою частіше припадають на кінець навчального дня або проводяться у формі факультативу, що спонукає студентів уникати занять фізичною культурою.
Перша причина, на думку авторів, - перевтома від навчального процесу, друга причина - нехтування формою проведення навчального заняття.

Так, думка авторів статті знаходить підтвердження в роботах науковців, зазначених нижче.

Фахівець 3 медицини В. Загородній зі співавтором (2021р.) перелічує безліч факторів, які негативно впливають на функціональний стан студентів. «Фактори робочого середовища (фізичний, фізіологічний, соціальний, психологічний, біологічний, естетичний); фактори процесу роботи (тяжкість та інтенсивність роботи); індивідуальні особливості молоді. Під час навчання стресорами для студентів можуть бути: велике інтелектуальне навантаження, недостатність часу, зокрема й на відпочинок та сон, стресові перевтоми, необхідність адаптації до нової організації навчального процесу, невизначеність майбутнього працевлаштування в умовах постійних змін ринку праці. Інтенсивне використання в навчальному процесі ЗВО сучасних інформаційних технологій приводить до посилення розумової діяльності, психофізіологічних навантажень із-за необхідності опанування великих обсягів знань і практичних навичок. Як наслідок, збільшується ризик негативних змін функціонального стану систем організму студентів, нормального перебігу фізіологічних процесів, що поступово призводить до негативних змін у стані їхнього здоров'я. Негативно впливає на функціональний та фізичний стан студентів малорухомий спосіб життя як у робочі дні тижня, так і у вихідні дні» [5, с. 58].

Науковці Т. Барсукова, Ж. Антіпова (2021 р.) зазначають, що в більшості студентів не до кінця сформована культура власного здоров'я засобами фізичної культури [7, с. 24].

Ученні І. Сопотова, О. Півень (2021 р.), зауважують, що організація процесу фізичного виховання у ЗВО України реалізується ще на підставі традиційних підходів і не відповідає світовим та європейським стандартам, тому що проходить без активного використання інноваційних технологій [6, с. 91]. Тобто зростає необхідність у проведенні тренувальних занять із виду спорту безпосередньо на уроках фізичної культури, що буде спонукати студентів до активної фізичної діяльності.

Останніми роками популярність такого виду спорту, як бокс, стрімко зросла в чоловіків, особливо в жінок, що пов'язано, на думку авторів статті, по-перше, $з$ маскулінізацією суспільства та висвітленням змагань різного рівня в засобах масової інформації, а також заснуванням громадських організацій, які ставлять за мету розвинення студентського боксу, по-друге, 3 досить різнобічним впливом спеціальних фізичних боксерських вправ на розвиток фізичних якостей, сенсорної системи, інтелекту (пам'ять усіх 
видів, антиципація, абстрактне та просторове аналітичне мислення). Звісно, бокс $є$ одним із видів спорту, у якому під час тренування задіяна максимальна кількість м'язів, визначається різноманітність видів вправ та висока координація фізичних вправ, що знаходить підтвердження в наукових роботах зазначених нижче авторів. Боксери мають пропорційну статуру 3 розвинутою мускулатурою. У процесі занять боксом під впливом тренувальних навантажень зміцнюється опорно-руховий апарат, розвиваються різноманітні рухові якості, особливо швидкість, швидкісно-силові якості, сила, точність, як наслідок, активізуються всі основні життєво важливі функції. Різноманітні вправи впливають на всі групи м'язів, нервову, судинну, дихальну і травну системи людини. Визначається позитивний вплив занять боксом на розвиток рухових і психічних функцій, виховання моральних та вольових якостей дає змогу розглядати бокс не тільки як вид спорту, але і як потужний засіб фізичного виховання й удосконалення особистості студентів. Заняття боксом виховують в особистості сміливість, мужність, виробляють швидкість реакції, здатність швидко i холоднокровно орієнтуватися у складних життєвих обставинах [8, с. 467].

Емпіричні дані засвідчують підвищення рівня фізичної підготовки у студентів засобами боксу.

Науковець В. Назимок (2014р.) зазначає покращення результатів у базових нормативах iз фізичної підготовки студентів I-II курсів КПІ, які займалися боксом. За показниками з фізичних нормативів, стрибки в довжину 3 місця 3 результатом 212 см на початку навчального року та $217 \mathrm{~cm}$ у кінці навчального року у студентів першого курсу. У студентів другого курсу показники теж збільшилися 3219 см до 225 см. Така тенденція спостерігалась у нормативі згинання та розгинання рук в упорі лежачи за 20 секунд 3 показниками кількості виконання від 28 до 29 у студентів першого курсів та від 30 до 31 у студентів другого курсу. Також підвищення результатів зазначено в цьому нормативі за 1 хвилину, від 50 до 52 за кількістю разів у студентів першого курсу та від 54 до 56 у студентів другого курсу. У бігу на 3000 м показали такі результати: 13,34 с на початку навчального року та 13,23 с наприкінці навчального року у студентів першого курсу, тенденцію зменшення часу виконання нормативу показали і студенти другого курсу з результатом 13,26 с на початку навчального року i 13,09 с у кінці навчального року [3, с. 194-195].

Дослідження, проведені в цьому напрямі іншими науковцями, доводять також підвищення рівня фізичної підготовки у студентів щодо складання нормативів 3 бігу на 30 метрів із низького старту, у якому динаміка розвитку фізичних яко- стей підвищилась на 6,2\%, у стрибках у довжину 3 місця приріст становив 5,2\%, підтягування у висі на перекладині показало підвищення фізичних якостей на 59,5\% [4, с. 27-28].

В експериментах із визначенням швидкості рухової реакції реагування на зоровий подразник серед індивідів, які відвідували курси водіїв, краща реакція виявилась у тих, що займаються боксом [9, с. 108].

Тобто, як доводять вищезазначені матеріали, заняття фізичною культурою за допомогою засобів боксу не тільки підвищують фізичні якості, a i впливають на розвиток реакції різного виду сенсорних систем, які знадобляться у засвоєнні спеціальностей, представлених в агротехнологічних 3ВО. Основна кількість навчальних програм iз боксу, за якими здійснюють навчання у ЗВО, та методи викладання, за описом таких науковців, як В. Вихор (2011 р.), І. Юрченко (2018 р.), складається 3 навчально-тренувального підрозділу, що включає 84 години, спрямований на підвищення рівня фізичної підготовленості та розвиток фізичних якостей, освоєння технічних дій, підготовку студентів до участі у спортивно-масових заходах. Зміст навчально-тренувального підрозділу включає техніку боксу (бойова стійка, пересування рингом, бойові дистанції, удари, захист, контрудари, серії ударів і захисту від них), тактику бою (наступальні й оборонні дії, умови бою на різних дистанціях, тактична організація бою), вправи, спрямовані на освоєння цієї техніки й тактики (загальнорозвивальні, спортивно-допоміжні, спеціальні, зокрема, імітаційні, вправи з боксерськими снарядами, бойові вправи 3 партнером). Методико-практичний підрозділ складається із шести навчальних годин (чотири години в першому семестрі, дві - у другому), який спрямований на освоєння методики підбору фізичних вправ, складання комплексів загальнорозвивальних i спеціальних вправ для проведення підготовчої частини навчально-тренувального заняття, формування вміння здійснювати контроль і самоконтроль у процесі занять, страховку й самостраховку. Окрему увагу приділено організаційно-методичним прийомам навчання і тренування, серед яких виділяють головні: 1) групове засвоєння прийому під спільну команду тренера в одношеренговому строю (без партнера); 2) групове засвоєння прийому під спільну команду тренера у двошеренговому строю (з партнером); 3) самостійне засвоєння прийому за завданням тренера в парах, які вільно пересуваються залом, майданчиком; 4) умовний бій з обмеженими конкретним вузьким завданням діями партнерів; 5) умовний бій із широко поставленими техніко-тактичними завданнями; 6) вільний бій (двобій без обмежень дій партнерів) [4, с. 25; 8, с. 467]. 
На думку авторів статті, такі програми розраховані на тренування в закладах спеціальної фізичної освіти, які висувають більш високі вимоги до студентів, але їх можна проводити у формі факультативу з більш зацікавленим контингентом. Безперечно, такі програми сприяють підвищенню фізичних якостей, що доводять дані досліджень вищевказаних авторів, але варто зауважити, що зазвичай у спеціалізовані 3ОВ у галузі фізичного виховання потрапляють індивіди 3 певним спортивним стажем, тобто такі вимоги обгрунтовані. Тому для студентів агротехнологічних 3ВО доцільно розробити власні авторські тренувальні методики, які будуть орієнтовані на визначений контингент за спеціальністю у 3ОВ, тому що інтелектуальних спеціальностей в агротехнологічних ЗОВ більше порівняно із закладами фізичної культури, і будуть орієнтовані за статтю.

Авторами статті проаналізовано такі тренувальні програми, як ModBox (розроблено Австралійськім офісом розвитку спортивної освіти в Індіï), що останнім часом набувають популярності (особливо серед дівчат) та введені навіть у 20 загальноосвітніх школах північних штатів Індії. Також у зв'язку з популярністю цієї програми, завдяки якій значно зросли показники відвідування молоді, надають свої тренувальні бази всесвітньо відомі приватні школи Індії, наприклад Doon Schul [10].

ModBox - програма, у якій основний акцент зроблено на поліпшення емоційного стану, гармонійного розвитку та безпеку учнів, що досягається застосуванням спеціальних тренувальних рукавиць, забороною ударів у голову [11]. Також проаналізовані авторські тренувальні програми під час підготовки висококваліфікованих боксеров-юнаків Ф. Гатіна, І. Колесника (2016р.), у яких методика викладання техніки і тактики основана на розвитку інтелектуальної складової частини в боксі, різноманітному застосуванні ii на спеціальних боксерських снарядах. Прикладом відпрацювання ударів можуть бути удари на боксерському мішку, стоячи один проти одного, із завданням одному з боксерів передбачати і випереджати удари суперника, наносити їх по боксерському мішку [12]. Це також дозволяє уникнути прямого контакту та знижує ризик травматизму. Тренувальна програма науковця I. Малазонія (2016 р.) заснована на використанні умовно контактних вправ, тобто відпрацюванні технічних дій із партнером у парі відбувається лише дотиком до цілі або по долоням супротивника [13].

На думку авторів статті, поєднання навчальних і авторських програм, зазначених вище, без умовних боїв із більш складними техніко-тактичними завданнями і двобоїв будуть актуальні. Навчання може бути основане на підготовчих вправах, які використовують під час тренування в боксі залежно від статі та фізичного розвитку. Так, вправи дозволять звести до мінімуму контакт між партнерами під час відпрацювання спеціальних боксерських вправ, що зменшить ризик отримання спортивних травм.

Фахівці з боксу вважають, що в навчанні техніко-тактичної підготовки в боксі чоловічої та жіночої статі визначено складник: послідовність навчання техніки ударів, пересувань, захисних дій та фундаментальних методів навчання. Однак автори статті зосереджують увагу на викладанні вищезазначеного за гендерно диференційним підходом, який основується на врахуванні у процесі занять фізичними вправами (тренування) менструального циклу (далі - МЦ) [14, с. 60-71].

Науковці, які працюють із жінками-спортсменками протягом десятиліть, доводять, що фази менструального циклу впливають не тільки на тренувальний процес, а також на показники спортивного результату і поведінки під час тренувань та змагань. Для предменструальної, овуляторної і менструальної фаз МЦ характерно зниження швидкості латентного періоду простої зорово-моторної реакції і складних зорово-моторних реакцій, зниження швидкості зміни процесів збудження і гальмування в центральній нервовій системі $[15$, с. 66-69]. Зазначають найменшу економічність кровообігу та використання енергетичних ресурсів організму під час фізичного навантаження, уповільнення рухової реакції, зниження сили, витривалості, збільшення рухливості в суглобах та розтяжність зв'язкового апарату. Потовиділення під час фізичного навантаження починається раніше, що відображається на чутливості до підвищення температури навколишнього середовища. Адаптація до фізичних навантажень стає більш напруженою, а відновлювальний період затягуватиметься [16]. Дослідження щодо 974 спортсменок у різних видах спорту, зокрема і в ациклічних видах спорту, довели, що у фазі менструації ефективність тренувань низка і становить від 43,5 до 80,3\% залежно від виду спорту $[17$, c. $3-14]$

Дані фахівців у спортивній медицини доводять вплив фаз МЦ на латеральну асиметрію, яка негативно впливатиме на рівень засвоювання координаційних вправ, рівень функціональної асиметрії взагалі, хоча за даними фахівців із психофізіології, у жінок загалом мала різниця в мануальній асиметрії порівняно із чоловіками $[18$, с. $14-19$; 19, с. 33-41]. Учені доводять, що жінки в окремі періоди МЦ складніше вирішують просторові завдання [20], більше схильні до підвищення рівня тривожності, неуважності [21], ризику збільшення травматизму нижніх кінцівок, ніж хлопці взагалі [22], а в деяких фазах МЦ такий 
ризик зростає [23], тобто у вищезазначених матеріалах доведена доцільність викладання за гендерно диференційним методом. Також, виходячи із власного багаторічного тренерського досвіду, автор статті вважає, що пріоритет у тренуваннях варто віддавати ігровому методу, який актуальний для різної спортивної кваліфікації, що доведено у власних наукових роботах [24; 25], у яких навіть висококваліфіковані дівчата-боксери на тренуваннях виявляють вподобання до подання матеріалу за допомогою ігрових засобів.
Висновки. У статті обгрунтовано доцільність навчання засобами боксу на уроках фізичного виховання, що, по-перше, підвищить мотивацію до занять фізичною культурою, по-друге, сприятиме формуванню навичок щодо визначеного виду спорту, по-третє, підвищить загальний рівень фізичної підготовки. Навчання гендерно диференційним та ігровим методами набуває актуальності особливо щодо жіночої статі. Навчальну програму для студентів доцільно базувати на підготовчих вправах кваліфікованих боксерів.

\section{ЛІТЕРАТУРА}

1. Методичне забезпечення ефективності функціонування системи фізичного виховання студентів вищих навчальних закладів України / Г. Грибан та ін. Вісник Чернігівського національного педагогічного університету. Серія «Педагогічні науки». 2017. Вип. 143. С. 8-10.

2. Мичка I. Формування мотиваційно-ціннісного ставлення студентів до занять 3 пауерліфтингу в освітньому процесі з фізичного виховання. Науковий часопис Національного педагогічного університету імені М.П. Драгоманова. Серія № 15 «Науково-педагогічні проблеми фізичної культури (фізична культура і спорт)». 2018. Вип. 5 (99). С. 121-124.

3. Назимок В. Фізична підготовленість студентів, що займаються боксом у процесі фізичного виховання. Науковий часопис Національного педагогічного університету імені М.П. Драгоманова. Серія № 15 «Науково-педагогічні проблеми фізичної культури (фізична культура і спорт)». 2014. Вип. 3К (45). С. 192-196.

4. Вихор В. Удосконалення фізичної підготовки студентів засобами боксу. Фізичне виховання, спорт $i$ культура здоров'я у сучасному суспільстві : збірник наукових праць. 2011. № 1 (13). С. 25-28.

5. Загородній В., Ярославська Л. Обгрунтування необхідності перебудови процесу фізичного виховання в навчальних закладах на основі показників фізичного розвитку, фізичної підготовленості та функціонального стану систем організму студентів. Науковий часопис Національного педагогічного університету імені М.П. Драгоманова. Серія № 15 «Науково-педагогічні проблеми фізичної культури (фізична культура і спорт)». 2021. № 8 (139). С. 57-63. DOI: 10.31392/NPU-nc. series15.2021.8(139).09.

6. Сопотова О., Півень О. Удосконалення навчального процесу з фізичного виховання з урахуванням інтересів студентів. Науковий часопис Національного педагогічного університету імені М.П. Драгоманова. Серія № 15 «Науково-педагогічні проблеми фізичної культури (фізична кульmypa i cnopm)». 2021. № 8 (139). C. 90-93. DOI: 10.31392/NPU-nc.series15.2021.8(139).15.

7. Басукова Т., Антіпова Ж. Оздоровчий фітнес як засіб формування у студенток усвідомленої мотивації до фізичної активності. Науковий часопис Національного педагогічного університету імені М.П. Драгоманова. Серія № 15 «Науково-педагогічні проблеми фізичної культури (фізична кульmypa i cnopm)». 2021. № 8 (139). C. 23-28. DOI: 10.31392/NPU-nc.series15.2021.8(139).04.

8. Юрченко І. Бокс у системі фізичного виховання студентської молоді. Молодий вчений. 2018. № 2 (54, лютий). С. 466-469.

9. Фарфель В. Управление движениями в спорте. Москва : Советский спорт, 2011. 202 с.

10. URL: https://www.sportanddev.org/en/search/content/content/article_content/field_sport_fld/boxing36? search=boxing (дата звернення: 21.02.2020).

11. URL: https://www.sportanddev.org/en/article/news/overview-and-update-modbox-india (дата звернення: 21.02.2020).

12. Гатин Ф., Колесник И. Концептуальные основы совершенствования спортивного мастерства квалифицированных боксеров. Педагогико-психологические и медико-биологические проблемы физической культуры и спорта. 2016. Т. 11. № 3. С. 8-15. DOI: 10.14526/01_1111_119.

13. Малазония И. Технико-тактическая подготовленность юных боксеров на начальном этапе спортивной подготовки. Теория и методика спортивной тренировки. 2016. № 4. С. 20-22.

14. Konoch A., Vorontsov A. Differential gender approach for girls of the age of 12-15 in the process of boxing training. PNAP. 2021. Vol. 44. № 1. P. 60-71. DOI: 10.23856/4407.

15. Шахлина Л., Чистякова М. Психофизиологические особенности спортсменок, специализирующихся в дзюдо. Вісник Камьянещь-Подільського нащіонального університету імені Івана Огієнка. Серія «Фізичне виховання, спорт і здоров'я людини». 2020. Вип. 18. С. 66-69. DOI: 10.32626/23098082.2020-18.66-69. 
16. Шахлина Л. Проблемы полового диморфизма в спорте высших достижений. Теория и практика физической культуры. 1999. № 6. URL: http://sportlib.info/Press/TPFK/1999N6/p51-55.htm (дата звернення: 21.02.2019).

17. Шахлина Л., Ковальчук Н. Современное представление об особенностях спортивной подготовки женщин. Спортивна медицина і фізична реабілітащія. 2018. № 1. С. 3-14.

18. Воронцов А. Засоби білатерального навчання в тренуванні дівчат та юніорок у боксі. Науковий часопис Національного педагогічного університету імені М.П. Драгоманова. Серія № 15 «Науково-педагогічні проблеми фізичної культури (фізична культура і спорт)». 2020. № 4. (124). С. 14-19. DOI: 10.31392/NPUnc.series15.2020.4(124).02.

19. Воронцов А. Значення функціональної асиметрії в разі вдосконаленні техніко-тактичної підготовки у жіночому боксі. Збірник наукових прачь Харківського державного університету. Серія «Педагогічні науки». 2020. № 90. С. 33-41. DOI: 10.32999/ksu2413-1865/2020-90-6.

20. Бендас Т. Гендерная психология . Санкт-Петербург : Питер, 2006. С. 431.

21. Presence and Perceptions of Menstrual Dysfunction and Associated Quality of Life Measures Among High School Female Athletes / A. Armento et al. J Athl Train. 2021.Vol. 56. Issue 2 (feb.). DOI: 10.4085/624-20.

22. Gender and age related differences in leg stiffness and reactive strength in adolescent team sports players / M. Lehnert et al. Journal of Human Kinetics. 2020. № 74. P. 119-129. DOI: 10.2478/hukin-2020-0020.

23. Lee H., Petrofsky J. Defferences between men and women in balance and tremorin relation to blantarfascia laxity during the menstrual cycle. Journal of Athletic Training. Vol. 53. № 3 (mart). P. 255-261. DOI: 10.4085/1062-6050-2-17 (дата звернення: 18.02.2019).

24. Воронцов А. Використання ігрового методу в тренуваннях з боксу дівчат в групах базової підготовки. Сучасні проблеми фізичного виховання і спорту різних груп населення : матеріали Міжнародної науково-практичної конференції молодих учених : у 2-х т. / відп. ред. Я. Копитіна ; наук. ред. О. Томенко. Суми : СумДПУ ім. А.С. Макаренка, 2019. Т. 1. С. 221-224.

25. Vorontsov A. An integrated approach to training girls in boxing. Relevant trends of scientific research in the countries of central and Eastern Europe: international scientific conference. Riga : Publishing House "Baltija Publishing". 2020. P. 195-198. DOI: 10.30525/978-9934-26-002-5-55.

\section{REFERENCES}

1. Hryban, H.P., Krasnov, V.P., Osypenko, V.Ye. \& Aiunts, V.I. (2017). Metodychne zabezpechennia efektyvnosti funktsionuvannia systemy fizychnoho vykhovannia studentiv vyshchykh navchalnykh zakladiv Ukrainy. Visnyk Chernihivskoho natsionalnoho pedahohichnoho universytetu. Seriia "Pedahohichni nauky", 143, 8-10. [in Ukrainian].

2. Mychka, I.V. (2018). Formuvannia motyvatsiino-tsinnisnoho stavlennia studentiv do zaniat z pauerliftynhu v osvitnomu protsesi z fizychnoho vykhovannia. Naukovyi chasopys NPU imeni M.P. Drahomanova. Seriia № 15: Naukovopedahohichni problemy fizychnoi kultury (fizychna kultura i sport), 5 (99), 121-124. [in Ukrainian].

3. Nazymok, V. (2014). Physical preparedness of students involved in boxing in the process of physical education. Naukovyi chasopys NPU imeni M.P. Drahomanova. Seriia № 15: Naukovopedahohichni problemy fizychnoi kultury (fizychna kultura i sport), 3K (45), 192-196. [in Ukrainian].

4. Vykhor, V. (2011). Students' physical fitness improving by means of box. Fizychne vykhovannia, sport $i$ kultura zdorovia u suchasnomu suspilstvi: zbirnyk naukovykh prats, № 1 (13), 25-28. [in Ukrainian].

5. Zagorodniy, V. \& Yaroslavska, L. (2021). Justification of the need for changing the process of physical education in educational institutions based on indicators of physical development, physical preparedness and functional state of studetns' body system. Naukovyi chasopys NPU imeni M.P. Drahomanova. Seriia № 15: Naukovopedahohichni problemy fizychnoi kultury (fizychna kultura i sport), № 8 (139), 57-63. [in Ukrainian].

6. Sopotova, I. \& Piven, O. (2021). Improving the educational process in physical education, taking into account the interests of students. Naukovyi chasopys NPU imeni M.P. Drahomanova. Seriia № 15: Naukovopedahohichni problemy fizychnoi kultury (fizychna kultura i sport), № 8 (139), 57-63. DOI: 10.31392/ NPU-nc.series15.2021.8(139).15 [in Ukrainian].

7. Barsukova, T. \& Antipova, Zh. (2021). Health fitness as a means of formation in students of conscious motivation to physical activity. Naukovyi chasopys NPU imeni M.P. Drahomanova. Seriia № 15: Naukovopedahohichni problemy fizychnoi kultury (fizychna kultura i sport), № 8 (139), 23-28. DOI: 10.31392/ NPU-nc.series15.2021.8(139).04 [in Ukrainian].

8. Yurchenko, I.V. (2021). Box in the system of physical education of student young people. Young Scientist, 2 (54, February), 466-469. [in Ukrainian]. 
9. Farfel, V.S. (2011). Upravlenie dvizheniyami v sporte [Motion control in sports]. Moscow: Sovetskij sport. [in Russian].

10. URL: https://www.sportanddev.org/en/search/content/content/article_content/field_sport_fld/boxing-36? search=boxing [in English].

11. URL: https://www.sportanddev.org/en/article/news/overview-and-update-modbox-india [in English].

12. Gatin, F.A. \& Kolesnik, I.S. (2016). Conceptual basis of sportsmanship improvement among qualified boxers. Pedagogiko-psihologicheskie i mediko-biologicheskie problemy fizicheskoj kultury i sporta, № 11, 3, 8-15. DOI: 10.14526/01_1111_119 [in Russian].

13. Malazoniya, I. (2016). Technical-tactical training of young boxers on the ascending stage of sports activity. Teoriya i metodika sportivnoj trenirovki, № 4, 20-22. [in Russian].

14. Konoch, A., Vorontsov, A. (2021). Differential gender approach for girls of the age of 12-15 in the process of boxing training . PNAP, 44, 1, 60-71. DOI: 10.23856/4407 [in English].

15. Shakhlina, L. \& Chistyakova, M. (2020). Psihofiziologicheskie osobennosti sportsmenok, specializiruyushihsya $\mathrm{v}$ dzyudo [Psychophysiological features of female athletes who are engaged in judo]. Visnyk Kamianets-Podilskoho natsionalnoho universytetu im. Ivana Ohiienka. Fizychne vykhovannia, sport $i$ zdorovia liudyny, № 18, 66-69. DOI: 10.32626/2309-8082.2020-18.66-69 [in Russian].

16. Shahlina, L.G. (1999). Problemy polovogo dimorfizma v sporte vysshih dostizhenij [Problems of sexual dimorphism in elite sports]. Teoriya i praktika fizicheskoj kultury, 6. Retrived from: http://sportlib.info/ Press/TPFK/1999N6/p51-55.htm [in Russian]

17. Shakhlina, L.Y.-G. \& Kovalchuk, N.V. (2018). Sovremennoe predstavlenie ob osobennostyah sportivnoj podgotovki zhenshin. [A contemporary view of the peculiarities of female sports preparation]. Sportyvna medytsyna i fizychna reabilitatsiia. № 1, 3-14. [in Russian]

18. Vorontsov, A. (2020). Zasoby bilateralnoho navchannia $\mathrm{v}$ trenuvanni divchat ta yuniorok u boksi [Means of bilateral teaching in the training of girls and juniors in boxing]. Naukovyi chasopys NPU imeni M.P. Drahomanova. Seriia 15: Naukovo-pedahohichni problemy fizychnoi kultury (fizychna kultura $i$ sport). № 4 (124), 14-19. DOI :10.31392/NPU-nc.series15.2020.4(124).02 [in Ukrainian].

19. Vorontsov, A.I. (2020). The value of functional asymmetry in improving technical and tactical training in women's boxing. Collection of research papers "Pedagogical sciences", 90, 33-41. DOI: 10.32999/ ksu2413-1865/2020-90-6 [in English].

20. Bendas, T.V. (2006). Gendernaya psihologiya [Gender psychology]. St. Petersburg: Piter. [in Russian].

21. Armento A., VanBaak K., Seehusen C.N., Sweeney E.A, Wilson J.C. \& Howell D.R. Presence and Perceptions of Menstrual Dysfunction and Associated Quality of Life Measures Among High School Female Athletes. J Athl Train Vol. 56, Issue 2 (feb.), 2021. DOI: 10.4085/624-20 [in English].

22. Lehnert, M., De Ste Croix, M., Svoboda, Z., Elfmark, M., Sikora, O. \& Stastny P. (2020). Gender and age related differences in leg stiffness and reactive strength in adolescent team sports players. Journal of Human Kinetics, 74, 119-129. DOI: 10.2478/hukin-2020-0020 [in English].

23. Lee H. \& Petrofsky J. Defferences between men and women in balance and tremorin relation to blantarfascia laxity during the menstrual cycle. Journal of Athletic Training. Vol. 53. № 3 (mart). P. 255-261. DOI: 10.4085/1062-6050-2-17 [in English].

24. Vorontsov, A.I. (2019) Vykorystannia ihrovoho metodu $\mathrm{v}$ trenuvanniakh $\mathrm{z}$ boksu divchat $\mathrm{v}$ hrupakh bazovoi pidhotovky [Use of the game method in girls boxing training in basic training groups]. Proceedings of the Suchasni problemy fizychnogo vyhovannia i sportu riznykh grup naselennia (Ukraine, Sumy, May 23-24, 2019) (eds. Kopytna Y.M, Tomenko O.A.), Sumy: SumDPU im. A.S. Makarenko, vol. 1, pp. 222-224. [in Ukrainian].

25. Vorontsov A. An integrated approach to training girls in boxing. Relevant trends of scientific research in the countries of central and Eastern Europe: international scientific conference. Riga : Publishing House "Baltija Publishing". 2020. P. 195-198. DOI: 10.30525/978-9934-26-002-5-55 [in English]. 